The challenges of commissioning home care for older people in England: commissioners' perspectives

Karen Davies, University of Manchester, Oxford Road, Manchester M15 6JA karen.davies3@manchester.ac.uk

Elizabeth Dalgarno, University of Manchester, Oxford Road, Manchester M15 6JA elizabeth.dalgarno@manchester.ac.uk

Susan Davies, University of Manchester, Oxford Road, Manchester M15 6JA susan.I.davies@manchester.ac.uk

Amy Roberts, University of Manchester, Oxford Road, Manchester M15 6JA amy.roberts@manchester.ac.uk

Jane Hughes, University of Nottingham, Institute of Mental Health, University of Nottingham Innovation Park, Jubilee Campus, Triumph Road, Nottingham, NG7 2TU jane.hughes@nottingham.ac.uk

Helen Chester, University of Nottingham, Institute of Mental Health, University of Nottingham Innovation Park, Jubilee Campus, Triumph Road, Nottingham, NG7 2TU helen.chester@nottingham.ac.uk

Rowan Jasper, University of Manchester, Oxford Road, Manchester M15 6JA rowan.jasper@manchester.ac.uk

David Wilson, Tameside Metropolitan Borough Council, Tameside One, Market Place, Ashton-under-Lyne, Tameside, OL66BH dave.wilson1@tameside.gov.uk

David Challis, University of Nottingham, Institute of Mental Health, University of Nottingham Innovation Park, Jubilee Campus, Triumph Road, Nottingham, NG7 2TU

David.Challis@nottingham.ac.uk 


\section{The challenges of commissioning home care for older people in}

\section{England: commissioners' perspectives}

\section{Abstract}

Home care for older people in England is commissioned through local authorities working predominantly with independent providers of care. Commissioners operate in a market model, planning and procuring home care services for local populations. Their role involves 'managing' and 'shaping' the market, to ensure an adequate supply of care providers. Another imperative, emerging from the principles of personalisation, is the drive to achieve user outcomes rather than 'time and task' objectives. Little formal research has investigated the way commissioners reconcile these different requirements and organise commissioning. This study investigated commissioning approaches using qualitative telephone interviews with ten commissioners from different local authorities in England. The characteristics of commissioning were analysed thematically. Findings indicated (i) commissioning policy involved complex systems and processes, uniquely shaped for the local context, but frequently changed, suggesting a constant need for reframing commissioning arrangements; (ii) partnerships with providers were mainly transactional, with occasional examples of collaborative models, that were considered to facilitate flexible services more appropriate for commissioning for personalised outcomes; (iii) only a small number of commissioners had attempted to reconcile the competing and incompatible goals of tightly prescribed contracting and working collaboratively with providers. A better understanding of flexible contracting arrangements and the hallmarks of a trusting collaboration is required to move beyond the procedural elements of contracting and commissioning. 


\section{Key words: home care providers, commissioning, contracting, collaboration, older}

\section{people}

\section{Introduction}

Policy and legislation relating to home care for older people in England sets out a strategy for the way services should be procured and delivered based on contracting between the public sector and independent providers (Department of Health and Social Care, 2018). Commissioning policy, underpinned by the theory of contracting, has evolved over many years, with the emphasis changing from a simple purchaser - provider model, that in retrospect failed to deliver more effective public services (Davies, Nutley and Smith 2000; Knapp, Hardy, Forder 2001), to a commissioner - provider arrangement. Currently a commissioning cycle is used, with activities intended to ensure publicly funded services in social care and health are appropriately sourced and monitored, delivering necessary outcomes for service users (Department of Health, 2014; Kings Fund, 2017). Changes in policy have been shaped by political and ideological drivers, rather than empirical evidence (Davies, Nutley and Smith 2000), potentially resulting in commissioning plans that lack a clear rationale and coherence. This paper presents the views of commissioners regarding commissioning arrangements with independent home care providers. It investigates the implications of contracting and collaborating on service quality and identifies some of the barriers to successful commissioning experienced by local authority commissioners in England. The motivation for the study stemmed from our engagement with commissioners in previous research that indicated that practice was diverse and prone to significant challenges (Chester, Hughes and Challis, 2010). Details of these challenges are rarely reported in the research literature and a better understanding of what commissioners are doing to resolve them, and how satisfied they are with the solutions, could support the development of more effective commissioning in the future, potentially fulfilling the imperative for person centred practice in home care delivery. This is set in the context of previous studies of commissioning to identify general issues 
relating to commissioning in public services and then appraise studies specifically investigating commissioning of home care for older people.

Commissioning practice typically involves assessing local needs, overseeing procurement of services and developing service specifications as part of a competitive contracting process. It demands a complex set of skills and knowledge, but may not include an understanding of the underpinning ideology and how this is changing (Bamford, 2013). The once hegemonic belief that a market model in commissioning can enable client choice and improve quality of services is now considered outdated (Bovaird 2006) with critiques of the model evident in health and social care sector in England (for example, lacobucci 2019). Policy directives have changed the expectations made of commissioners, with the role of local authorities in England in overseeing social care developing and changing over the last three decades. Responsibilities have changed from a direct provider of care to an enabling agency (Jasper et al., 2019). Successive government policies championed competition between providers as the mechanism to drive improvements. In doing so, local authorities were stepping into unknown and untested territory, adopting roles more usually found in commercial business, such as sourcing providers, negotiating contracts and monitoring arrangements. Nevertheless, as reforms have progressed, the emphasis has moved beyond a market model based on contractual arrangements to a shared endeavour to ensure local authorities 'embed the principle and practice of commissioning on the basis of quality, outcomes and value for money in their areas' and 'bring an end to commissioning practices that undermine people's dignity and choice.' (p $46 \mathrm{Cm} 8378,2012)$. However, changes, enshrined in the Care Act (2014) and amplified in statutory guidance (Department of Health and Social Care, 2018) for social care, continue to advocate 'managing' and 'shaping' the market. Commissioners are expected to enact high level guidance according to their own local context, potentially resulting in considerable variation in practice. The contractual arrangement between local authorities and home care providers, as independent businesses, is an exemplar of how a market model involving public-private partnerships not only operates in practice, but also alters over time. 
However, relatively little is known about what determines decision-making by commissioners of care services, as they interpret abstract requirements such as market shaping and management (Coleman, Checkland, Harrison 2009).

Previous analysis of models of commissioning, based on developments in health and social care, suggests three principal areas of interest: (i) the process of commissioning and contracting; (ii) the role of markets and competition; and (iii) commissioning relationships (Newman et al., 2012). According to these authors, the three elements are rarely considered together. For example, contracting literature identifies the typical characteristics of contracts for commissioning but infrequently links this to the nature of commissioning relationships or outcomes for service users. The different contracts employed in commissioning, such as oneoff exchanges or longer-term contracts (spot or block contracts), complete or incomplete contracts (highly specified/ closed or open ended), and explicit or implicit contracts (written or unwritten shared understandings) (Mackintosh 2000), may each assist or impede the provision of quality services in different ways. There is some evidence, for instance, suggesting that more open contracts encourage flexibility in service delivery that then facilitates more personalised care. This then offers greater choice for service users and opportunities for more meaningful relationships to develop between service users and care workers (Raynes et al., 2001; Van Slyke 2006; Glendinning et al., 2008). The growing interest in the notion of relational contracting (Bertelli and Smith, 2009), based on trust and collaboration rather than transactional contracting, features in health research, but is less evident in social care (for example, Porter et al., 2013). Some researchers have reasoned that relational contracts are particularly important for longer term arrangements, even viewing other contractual arrangements as 'dangerous', arguing that unanticipated difficulties can be accommodated when resilience and adaptability have been encouraged as part of long-term contract (Bovaird 2016).

Commissioning home care is an example where contracting from independent and voluntary sector providers has increased notably (more than ninety percent) over recent years (Holmes, 
2016). Three specific challenges for commissioners are associated with this change. First, commissioners have been expected to influence the entire home care market across a local area. The Care Act (2014) stipulated that commissioners should consider people who fund their own care in market shaping activities, given the potential role of self-funders in sustaining independent providers who also deliver care packages that are publicly funded. However, current research indicates that self-funders are largely unknown to authorities and so commissioners are now tasked with finding novel ways to understand the requirements and considerations of 'elusive' self-funders, who also contribute to market shaping (Henwood, 2019). Further challenges include the role of direct payments that individuals receive from local authorities, and how their allocation may also influence the market for home care (Moran et al., 2013)

Second, there is an intractable problem in gathering meaningful information regarding the overall effectiveness of outcome-based home care (Smith et al., 2017). Commissioners can respond to this information problem in two ways, first, demanding more and more data from providers, aided by technology and electronic monitoring, but not necessarily enabling care to be delivered in the best way. Alternatively, they can accept open contracts, endeavouring to build trust with providers dependent on a closer collaboration that proffers freedom to make decisions and manage service delivery with less tight scrutiny. Finally, commissioning guidance has encouraged a more flexible outlook to contracting, resulting in a range of different types of contracts used in any combination. Commissioners are using 'spot' contracts, 'block' contracts and 'framework agreements' across social care (Wilberforce, Baxter and Glendenning, 2012; Davies et al., 2019). Preferences for contract type are changing and commissioning arrangements are moving from block and spot contracts to framework agreements in the field of home care, with the assumption that this affords greater flexibility during the procurement process (Rodrigues and Glendinning, 2015). A framework agreement includes several approved providers for a locality, with set prices and standards, potentially 
assuring the supply of providers, but nevertheless generating disadvantages for care businesses, such as a lack of certainty and guaranteed workflow.

The complexities inherent in managing and shaping the market raise the question of how commissioners reconcile contradictory drivers, such as operating a market model, whilst introducing innovative solutions to improve the quality and quantity of care provision in a local market (Ware et al., 2003; Rubery, Grimshaw, Hebson, 2013). They are faced with the option of either adapting practice to navigate the problems or maintaining the rigid application of a contracting model that may stifle progress. For example, providers, interviewed in one study, considered that commissioners were inflexible and risk averse, committed to a 'time and task approach' that restricted providers' efforts to deliver person centred care (Bottery, 2018). As the author points out, employing a 'time and task' method may be difficult to avoid in a tough competitive tendering process. Consequently, imperfect solutions are likely to be employed that involve contradictory discourses, such as the adoption of the language of new models whilst preserving old systems (Glendinning et al., 2006). Little is known about the ways commissioners navigate these difficulties and what is considered when adaptations to existing systems are made. This paper presents a study of the views of commissioners regarding commissioning arrangements with independent home care providers, investigating the implications of contracting and collaborating on service quality.

\section{Research Aims}

The research aims for the study were to evidence commissioners' approaches to arranging home care for older people in relation to:

1. Their perceptions about what they were expected to do

2. Their perceptions about the constraints they believed they needed to take into account

3. Their identification of, and response to, challenges they were trying to resolve and their perception of the success of this resolution. 


\section{Methods}

\section{Study design}

The study addresses the knowledge gap of seeking to understand how commissioners of home care for older people are trying to manage and shape the market as required by the Care Act (2014). A qualitative method was employed to identify differences between commissioners and how they saw their role and responsibilities. This provided the opportunity to explore, in depth, their expectations, experiences and difficulties, in order to reveal the challenges of operating in a market model. The paper presents the qualitative phase of a mixed method study of home care arrangements investigating changes in commissioning arrangements in England (redacted for review). Within the scope of the study, views of commissioners of home care services in ten local authority areas in England were collected using semi-structured interviews. Local authorities were carefully selected from a national survey of all English local authorities conducted in the wider study (Davies et al., 2019)

The study conformed to ethical guidelines for telephone interviewing with informed consent gained over the phone and recorded on a consent form by the researcher. Ethical approval was given by the Social Care Research Ethics Committee (17/IEC08/0016).

\section{Recruitment and participants}

Local authorities were selected according to their responses to a national survey conducted in the first stage of the study (Davies et al., 2019). Authorities were grouped reflecting their collective approach to commissioning. This was based on responses relating to contracting arrangements, provider consultation and contribution to specifications and use of providers who subcontracted services as part of their responsibility for the local authority contract. Local authority commissioners, representing different ways of working, were approached and agreed to participate. They were invited to take part in the study via an email that included an explanation of the study and information about the data collection. Commissioners replied to the study team via email to arrange a telephone interview. 


\section{Data collection}

The research team developed a topic guide for semi-structured interviews using issues raised in previous studies and guided by an advisory group of researchers and advisers from the home care and commissioning sector (Table 1). This was trialled initially with one commissioner prompting changes to the format and wording of the interview questions. The interview guide comprised of five topic areas, with opportunity for prompts and follow-on questions to encourage participants to elaborate their responses (Breakwell, 2006). Each interview was audio recorded and took approximately 60 minutes to complete.

Table 1: Topic guide for commissioner interview Topic areas Interview questions

1. Background Tell me about your role and where it sits in your organisation

2. Current arrangements

3. Commissioning process

4. Quality assurance

5. Impact
What are your current arrangements with home care providers?

a. How many providers do you commission?

b. How do you work with your health partners in commissioning home care? [CCG role]

c. What determines the way you approach commissioning?

How would you describe the process of commissioning?

Who is involved in commissioning and when does this happen?

How long do your contracts last?

How is procurement undertaken and who does the procurement?

How would you summarise your approach to commissioning? What are the key components of effective commissioning and why do these matter?

How do you ensure the contracts are effective?

a. How do you collect data for monitoring?

What role do other parts of the organisation have? How does this affect commissioning arrangements?

How do you use CQC reports of home care providers?

How do these checks and balances contribute to service sustainability?

What difference does commissioning make to the services that people receive in your area?

Tell us about any developments you have (outcomes-based approach - ask what they mean by an outcomes-based approach) 
What is the Impact on staff in care providers and why is this?

6. Other Is there anything else you would like mention or add?

\section{Data Analysis}

Interviews were transcribed, coded and analysed using ATLAS.Ti 8 software to organise the data. A detailed thematic analysis of the interview transcripts was completed by two researchers (redacted for review) who conducted the initial coding independently. The researchers then agreed a set of codes together before identifying main and subsidiary themes. The analysis followed the six-phase process routinely used in qualitative research: familiarisation, generating codes, identifying themes, reviewing themes, and defining and interpreting themes (Braun and Clarke, 2006). This was an iterative process involving reviewing findings as the analysis progressed with the wider research team to challenge and corroborate interpretation and enable relationships between themes to be identified.

\section{Findings}

Ten local authority commissioners contacted by the research team agreed to participate in a telephone interview (Table 2). The structural variation in commissioning arrangements was evident in both the number of providers they worked with (two to 247), description of contract types and the combinations of contracting arrangements they employed. The themes derived from the analysis are presented using quotations from the commissioners, indicated as $\mathrm{C} 1$ C10.

Table 2: Participant characteristics

Number of providers

Type of contracts
Type of relationship with providers as described in interviews 


\begin{tabular}{|c|c|c|c|}
\hline C1 & $\begin{array}{l}1 \text { Primary } \\
17 \text { Subcontracted }\end{array}$ & $\begin{array}{l}\text { Domiciliary care } \\
\text { framework }\end{array}$ & Transactional \\
\hline $\mathrm{C} 2$ & $100+$ & $\begin{array}{l}\text { Block and framework; } \\
\text { multiple types of contracts }\end{array}$ & Collaborative \\
\hline C3 & $\begin{array}{l}36 \text { Primary and } \\
\text { Others }\end{array}$ & Joint framework contract & Transactional \\
\hline C4 & 17 & $\begin{array}{l}\text { Dynamic Purchasing } \\
\text { Framework and spot }\end{array}$ & Collaborative \\
\hline C5 & 247 & $\begin{array}{l}\text { Dynamic purchasing } \\
\text { system }\end{array}$ & Collaborative \\
\hline C6 & 2 Primary and others & Framework & Emerging collaboration \\
\hline $\mathrm{C} 7$ & 22 & Open framework & Emerging collaboration \\
\hline C8 & $\begin{array}{l}6 \text { Primary } \\
15 \text { others }\end{array}$ & Framework & Collaborative \\
\hline C9 & $\begin{array}{l}10 \text { Primary } \\
16 \text { Other }\end{array}$ & $\begin{array}{l}\text { Dynamic purchasing } \\
\text { system }\end{array}$ & Emerging collaboration \\
\hline C10 & $\begin{array}{l}3 \text { Primary } \\
120 \text { Other }\end{array}$ & Framework & Collaborative \\
\hline
\end{tabular}

This section presents salient themes identified from interviews with commissioners of home care (Table 3), displaying a spectrum of responses across the dimensions of contracting and collaborating with independent providers.

Table 3: Themes from commissioners' interviews

\section{Main theme}

1. Commissioners' role in contracting home care

\section{Subtheme}

Overseeing care arrangements and supporting providers

Setting direction, values and strategy for the locality 
Connecting internally and externally through networks

2. Relationship between commissioners and providers of home care

3. Applying and adapting a market model
Commissioning characterised by distant or collaborative relationships

Working collectively for personalised outcomes

Systems, processes and organisational developments

Chronic workforce issues

Theme 1: Commissioners' role in contracting home care

Many commissioners described working extensively to review and revise their approach to commissioning, drawing on national guidance, policy and good practice. Wholesale restructuring related to changes at the organisational level, including changes to local authority boundaries and team structures, influenced their role, as well locally agreed strategic priorities.

Commissioners reported enormous variation in how their roles were set up within their organisations and what the role entailed. Consequently, it was difficult to find a common definition, articulated by one commissioner, 'When you try to explain to somebody outside the local authority what commissioning is, it's not a simple...you just...in layman's terms you can't explain it in a simple way, so it's difficult.' (C6). Some reported that their role was principally strategic, understanding the local demands, supporting changes, for example through 'transformation of home care' (C8), and working with providers to accomplish new developments, 'we work with the market to develop those ideas' (C2). For others, the role also included operational aspects of commissioning such as setting up brokerage to acquire packages of care from providers, overseeing contracting and ensuring monitoring was in place. Commissioners' discourse revealed three essential features of their role: (i) overseeing care arrangements and supporting providers; (ii) setting the strategic direction for their locality and (iii) creating networks to achieve the aim of sustainable and reliable home care. 
Overseeing care arrangements and supporting providers involved setting up and maintaining contracts to ensure care was available for the population within an authority. It was presented as a mediating role, with some articulating a narrative of trying to pre-empt difficulties and proactively prevent business failure for providers. Mediating was closely associated with having an open dialogue with providers and for a few commissioners, the oversight role specifically included supporting providers who were not part of their current contracting framework.

The role involved scrutinising providers, but also overseeing the implications of commissioning on providers and the care that older people received. One commissioner explained that their role was 'working together with the market to improve quality and our focus as a council is to move away from time and task and focus more on the outcomes in relation to home care' (C4). Another (C3), observed that using a model based on hourly rates to determine contract arrangements was 'very reductive' and created a barrier between commissioners and providers through failing to fund elements which contributed to quality care.

The second role identified by commissioners was strategic leadership, explicitly described as setting a 'direction' of travel, with the implication that this changed and developed over time. However, commissioners rarely articulated the underpinning rationale for their strategy or the reasons for changing it. The most frequently cited strategic priority was an ambition to become more outcome focused, depending on working more closely with providers and changing inflexible contracts:

We're developing a very non prescriptive contract, that talks about outcomes for people.... working within a fixed procurement rules and regulations, can sometimes be counterproductive (C5).

There were examples of barriers to achieving their strategic priorities, such as the professional culture within public and private organisations, poor understanding of outcomes and 
reluctance to change practice and systems that used 'time and task' to monitor work and arrange payment:

At that time I didn't feel that the market was ready for that because we needed to do a lot of work towards developing a different way of working..... So to get to that stage, I felt that we needed to do more work with the providers and what we did include into the specification was that they would work in a re-abling way, so try to re-able people and not just hold onto them to say, right, they've got a package of care, we will keep onto them as long as we need to. (C6)

The third feature of the commissioners' role involved creating networks and working closely with other areas of the local authority and beyond to ensure smooth delivery of care. They often explained complicated organisational arrangements, where the commissioner was part of a complex network of commissioning, procurement, contracting and quality monitoring. Some were part of joint commissioning units across local authorities, but few jointly commissioned with health. An important network for some commissioners was with local providers who were regarded as bringing an understanding and connection to the community, in terms of local knowledge and commitment:

And actually working locally with your sector, tends to bring better results, it's a bit like people working locally within their communities isn't it? (C2)

In summary, commissioners operated in varied organisational structures and many had a broad portfolio of service responsibility, adopting a role of 'strategic oversight' without necessarily having in-depth knowledge of all areas within their remit.

\section{Theme 2: Relationships between commissioners and providers of home care}

Commissioning was characterised by distant or collaborative relationships with home care providers. Most interviewees were striving to improve the relationship with providers whilst also maintaining clear transactions in the form of contract specifications. However, commissioners reported tensions between contracting, that involved detailed and prescriptive 
specifications, and collaborating with providers, acknowledging that care could not be regarded as a transactional process, 'The minute care becomes transactional.....you start forgetting what it's about, and it's about the person that you're all striving to look after in the best possible way.' (C2).

The role of trust within a collaborative approach was also acknowledged, and regarded as an element that needed to be developed rather than assumed. There were a few commissioners who achieved closer relationships with providers through shared developments that involved reciprocal participation based on trust, going beyond 'engagement' or 'consultation':

I know everyone says it, but I think it is important to spend time building that relationship with the providers because they're the ones who are going to be delivering the service, so if you're thinking about different models, different ideas, getting their input into that as early as possible. (C4)

Regular meetings and forums between commissioners and providers were often quoted, but attitude rather than format or frequency of formal meetings featured strongly in the discourse. Indeed, some commissioners indicated that attitudes were undergoing significant changes, altering from an adversarial relationship to one of collaboration with providers:

We've developed quite a good dialogue with the providers, we have regular meetings and forums and I think probably a few years previously it was a bit more adversarial, a bit more confrontational, whereas now I think we've got more of a two-way conversation, we're listening, we're trying to work through issues together. (C4)

The description of relationship building as a 'tightrope' portrays the intensity of the challenges experienced, with attempts to balance different stakeholder perspectives, establish realistic measures for monitoring and manage a large and changeable demand. As the following commissioner illustrates, managing the competing perspectives of public sector professionals and independent care providers created complex interchanges within the sector: 
I think it's a sort of tightrope that we're walking on, in our relationship with providers. And often, we're aware that social workers are slightly uneasy with our relationship with providers. I think that they'll often be of the view that we give them too easy a ride, and that perhaps we should take, you know, we should come down harder on them, all that sort of stuff. (C8)

Working collectively for personalised outcomes was frequently cited as a key driver for future developments and often arose as part of the dialogue about collaboration with providers. In talking about outcomes, commissioners tended to fall into two groups, with those who expressed an intention to use outcomes to implement changes, but had little experience of the challenges, and those who had trialled initiatives based on outcomes and experienced difficulties in delivering outcomes-based commissioning. Those who had trialled different approaches had employed time and deliberation to commission care that was determined by outcomes rather than 'time and task' related activities. In the following quotation, the commissioner relates a more open contract with delivering outcomes, referring to a fundamental change in expectations and behaviour. In this extract, he/she referred to changing the culture across the social work teams to allow 'my providers' to adopt flexible working approaches:

We're developing a very non prescriptive contract, that talks about outcomes for people, and providers will get aid on the basis of delivering, in some cases, individual outcomes. So, we're working really hard with teams to change that culture, because all that does, is it allows my providers then, to be more flexible for the person as well.

There were accounts of unsuccessful initiatives, where commissioners had assumed they could trust providers with a flexible contract but discovered providers exploited the opportunity to make money, 'we paid an absolute fortune for a service that really wasn't very good quality and it wasn't particularly good for the people in receipt of the service' (C10). The dilemma of commissioning for outcomes without clear mechanisms for measuring success was a 
significant challenge and some commissioners described hybrid models that aimed to include the notion of outcomes as well as tightly timed delivery of care:

So, we had our fingers burnt a couple of times, so we've decided this time we really need to get it right. So our social care assessors are assessing for outcomes and we are commissioning on task and time. (C5)

Some interviewees commented on the need to 'shift roles' to providers, involving them more closely in assessment and reassessment of service user needs and care planning. Clearly, such a move would be dependent on a close working relationship between commissioner and provider and challenged current arrangements with professional boundaries for assessment, such as social workers, exerting a tension:

I think, you know, systematically we don't engage them [providers]. I think we absolutely need to change that model and we need to shift roles and responsibilities around considerably to bring assessment and...assessment needs analysis and provision and purchasing much closer together. (C3)

In summary, commissioners drew a distinction between transactional and relational approaches to working with care providers. This was impeded by constraints imposed by budgets, prescriptive contracts, untested drivers, such as outcome-based commissioning, and historical attitudes.

\section{Theme 3: Applying and adapting a market model}

Commissioners described balancing competing challenges during the commissioning and contracting of home care. On occasions, some of them explicitly expressed the contradictions and frustrations of trying to align a tight contracting process with encouraging greater flexibility. Various factors had contributed to these challenges including organisational restructures, changes to the process of tendering and procuring services, a legacy of hierarchical and adversarial approaches in contracting and managing responsibility for risk of service failure. They frequently referred to challenges outside their control concerning providers in the private 
sector, such as recruitment and retention of care staff by care businesses, or the impact of competition between providers and other employers outside care.

Systems, processes and organisational developments featured strongly in commissioners' discourse, emphasising the absence of a 'blueprint' for success. Most perceived previous time and task systems as limiting development and innovation linked to personalised outcomes. Many commissioners expressed the desire to replace tight contracting with a more flexible approach that encouraged service delivery that was more aligned with outcomes agreed with service users. There were reservations about how this would develop, with commissioners referring to issues relating to guidance, costing for outcomes, paying for services and potential disruption for service users:

I've seen some fab examples of where an outcome-based commissioning contract has worked, and is still working, and likewise l've seen ones that have failed miserably, because you don't understand some of the ramifications. But, for me, I always take it back to the outcomes to the individual, rather than thinking about outcome-based contracting, and stuff like that. (C2)

Although there were relatively few examples of positive progress in changing the culture in commissioning cited by the interviewees, those that were offered expressed a desire to move away from a transactional relationship with providers based on tightly specified contracting. Fixed procurement rules were identified as constraining commissioners' approaches and were presented as contributing to a hierarchical relationship with providers. Changing the focus from tightly prescribed activities to a more flexible approach was considered a monumental task:

It is a bit like turning round the super-tanker because time and task has been the way it has been forever and it's doing unto people, rather than working with people (C1) 
In the following example, the tension between implementing regulations and providing opportunities for developing flexible services that respond to service user's unique needs was expressed compellingly:

One thing that I would want people to explore is, people are not those widgets, therefore, to have them under the same regulations as buying tarmac, seems bananas to me.....But, I think we've proven, where you're allowed to test and learn, and push those boundaries a little bit, you can get better results. (C2)

Responsibility for managing risk in the supply of home care was a prominent theme in commissioners' discourse, emphasising the possible disruption to services. They attempted to address this by monitoring providers' performance on the front-line and overseeing the quantity and quality of providers within a locality. Employing framework agreements, with several organisations approved and potentially available to provide care, was regarded as one means of minimising the risk for commissioners of a reduced supply of providers.

We also have a domiciliary care framework...that's also a bit of an insurance policy for us, were the lead provider not to supply. (C1)

Nevertheless, adopting a framework arrangement could not necessarily guarantee an appropriate supply of providers. One example of a commissioner expanding the number of organisations meeting the framework requirements, resulted in moving from too few providers to too many, generating unanticipated difficulties in monitoring and supporting new care organisations. Examples of commissioners supporting individual organisations to avoid provider failure were cited, identifying those at risk from a risk profile and actively investigating and supporting the business:

We undertake a risk assessment and then those at highest risk, we'll go out and undertake what's called a baseline assessment visit where we do a site visit to the provider and look at their policies and procedures, their user feedback, care files, staff files and things like that. (C5) 
Commissioners described longstanding issues with recruiting and retaining staff: workforce capacity and competition between care providers was presented as a 'chronic' problem, relating not only to the pay of care workers but also their status. The division of responsibilities, with independent providers managing the workforce and commissioners ensuring the supply of care, left commissioners feeling vulnerable and only partially able to manage the deeprooted issue:

The fundamental issue we have at the moment is workforce. We really struggle to recruit for a range of reasons, in a range of areas. But that really drives where we see providers having problems, where we see people being stuck in hospital, the in-house service having to pick up. (C5)

Some perceived these issues were related to the working conditions for care workers, such as zero hours contracts, and managing difficult cases in the community. The implications of commissioning, such as using a 'time and task' model, was presented as a disincentive for workers, discouraging ongoing commitment to caring as a career:

I think it's to do with the lack of attractiveness of some of the roles, and that's directly attributable to the way we commission........ at the moment we still commission in a time and task manner..... the net effect on the worker is a role where you basically rush from place to place delivering personal care interventions in a very compressed manner. (C3)

Commissioners expressed concern about the status of care workers as a barrier to recruitment and retention. Many considered that raising the status of care work could go some way to addressing the workforce capacity issues. There was a view that raising the status of home care workers could reduce burdens elsewhere in the care system, such as hospital admissions: 
We also try to do is to raise the status and profile of care work within the sector because it's about... social care is a fundamental part of the capacity in the system........it's systematically underfunded and underinvested in. (C3)

\section{Discussion}

Little research to date has explored commissioners' experience of working with care providers in delivering home care. This study offers an in-depth investigation of commissioner perspectives using carefully selected participants from a national survey. The paper presents the perspective of commissioners on expectations, challenges and responses to challenges, using their descriptions and explanations of commissioning arrangements for home care for older people in England. The discussion draws on the three principal areas of interest identified by Newman et al., (2012): (i) the process of commissioning and contracting; (ii) the role of markets and competition and (iii) commissioning relationships. The characteristics of commissioning are presented using a conceptual framework developed to illustrate the relationship between collaboration and contracting as indicated by the discourse of the commissioners (figure 1).

Commissioners described commissioning arrangements as complex, unique to each individual local authority and dynamic, changing over time as directives, circumstances and personnel changed. It was, therefore, difficult to compare the detail of different models of practice or identify elements that contributed to successful commissioning in a market system. Such variation in concept and practice has been reported in other sectors (Davies and Davies, 2012; Newman et al., 2012) and is emerging as a concern internationally (Robinson, Dickenson, Durrington 2016).

\section{The process of commissioning and contracting}

Regardless of policy makers' intentions, commissioners have interpreted policy as requiring them to draw up closed contracts with detailed specifications. Commissioners illustrated how they adapted their approaches to working in a market model in response to different policy 
imperatives, championing apparently incompatible goals. They reported that tightly prescribed contracts and an adversarial, hierarchical approach were unworkable given that delivering some elements of care, such as emotional support, were impossible to prescribe in detail (Isaksson, Blomqvist and Winblad, 2018). Consequently, they were seeking ways to procure services that were less heavily prescribed. Current guidance in England (LGA, 2018) encourages commissioners to adopt a more flexible approach, including recommending closer collaboration with stakeholders. However, other essential guidance issued for commissioners, in the form of a revised commissioning cycle (LGA, 2018), continues to emphasise processes rather than relationships, as illustrated in the summary diagram where there is just one phrase that refers to joint practice. The phrase from the commissioning cycle, 'manage provider relationship' (p.6 LGA, 2018), conveys commissioners as controlling the relationships with providers, rather than expressing a relational or reciprocal approach. Whilst opinion in the sector refers to a 'deeply embedded' model that is in 'disarray' (Hudson, 2018), findings from this study appear to contradict this; in practice commissioners are finding ways to work around the challenges and attempt to avoid disarray, with many showing an ambition to adopt approaches that go beyond formal contracting and embrace collaboration with providers, however difficult and unpredictable this may be.

\section{The role of markets and competition}

The study demonstrated how determined some commissioners were to operate an open contracting model to achieve changes in the focus of commissioning, despite the challenges of monitoring and oversight necessary to demonstrate accountability to superiors. Many commissioners assumed a narrative that emphasised the importance of arrangements with providers of home care that enabled services to deliver outcomes rather than prescribed activities. However, there was a distinction between those who had already attempted to commission services according to outcomes and others who regarded it as an ambition, placed on a 'wish list' pending further work. Commissioners gave examples of frustrations and failed attempts at introducing approaches based on outcomes. This related to two principal 
problems: first how to define and specify outcomes that were meaningful to service users and second, how to monitor, measure and cost outcomes. Commissioners illustrated this by easily putting a cost on the time providers spent with a client, but struggling to specify how the time yielded specific outcomes.

In summary, commissioners' responses indicated that they found the two imperatives of competition, associated with a prescribed contract typical of a market model, and collaboration with providers, particularly challenging. Previous research has concluded that the two imperatives were incompatible (Hudson, 2013), noting that with open, flexible contracts problems exist in measuring outcomes, particularly in the context of home care.

\section{Commissioning relationships}

The present study suggests that commissioning relationships were changing and ranged on a continuum from partnerships that were mainly transactional through to those that were collaborative. Collaboration was linked in the discourses with shared problem-solving, developing services and focusing on outcomes. Many commissioners affirmed the importance of the relational, but fewer were able to exemplify how they achieved this. The trends evident in the commissioner-provider relationship as described by the commissioners in this study have been summarised in a conceptual framework to illustrate the differences between contractual and collaborative approaches (Figure 1).

Figure 1: The spectrum of commissioning approaches related to the relationship between commissioner and provider as described by commissioners of home care for older people

\begin{tabular}{llll} 
& Contractor & Emerging partner & Collaborator \\
\hline $\begin{array}{l}\text { Characteristics of } \\
\text { relationship }\end{array}$ & $\begin{array}{l}\text { Arm's length and } \\
\text { distant from provider }\end{array}$ & $\begin{array}{l}\text { Trialling small } \\
\text { projects with specific } \\
\text { providers }\end{array}$ & $\begin{array}{l}\text { Developing services } \\
\text { together with } \\
\text { providers }\end{array}$ \\
& $\begin{array}{l}\text { Little dialogue with } \\
\text { providers }\end{array}$ & $\begin{array}{l}\text { Dialogue associated } \\
\text { with specific issues }\end{array}$ & Open dialogue \\
& $\begin{array}{l}\text { Not trusting } \\
\text { providers }\end{array}$ & $\begin{array}{l}\text { Recognising the } \\
\text { benefits of trust }\end{array}$ & Trusting providers
\end{tabular}




\begin{tabular}{|c|c|c|c|}
\hline \multirow[t]{2}{*}{$\begin{array}{l}\text { Aims of } \\
\text { commissioners }\end{array}$} & \multirow[t]{2}{*}{$\begin{array}{l}\text { Few explicit shared } \\
\text { aims with providers }\end{array}$} & \multirow[t]{2}{*}{$\begin{array}{l}\text { Involving providers in } \\
\text { some projects }\end{array}$} & $\begin{array}{l}\text { Setting direction with } \\
\text { providers }\end{array}$ \\
\hline & & & $\begin{array}{l}\text { Values articulated } \\
\text { and shared with } \\
\text { providers }\end{array}$ \\
\hline \multirow{4}{*}{$\begin{array}{l}\text { Approaches to } \\
\text { contracting }\end{array}$} & Transactional & Partially collaborative & Mutually agreed \\
\hline & \multirow[t]{2}{*}{$\begin{array}{l}\text { Little } \\
\text { acknowledgement of } \\
\text { shared goals }\end{array}$} & \multirow[t]{2}{*}{$\begin{array}{l}\text { Recognising a } \\
\text { mutual purpose }\end{array}$} & $\begin{array}{l}\text { Goals between } \\
\text { commissioner and } \\
\text { provider are aligned }\end{array}$ \\
\hline & & & $\begin{array}{l}\text { Perceive role as joint } \\
\text { problem solver with } \\
\text { providers }\end{array}$ \\
\hline & $\begin{array}{l}\text { Closed } \\
\text { contract/highly } \\
\text { specified }\end{array}$ & $\begin{array}{l}\text { Trialling more flexible } \\
\text { contracts in some } \\
\text { areas }\end{array}$ & $\begin{array}{l}\text { Open } \\
\text { contract/flexible }\end{array}$ \\
\hline \multirow[t]{2}{*}{$\begin{array}{l}\text { Approach to } \\
\text { monitoring }\end{array}$} & Tight monitoring & \multirow[t]{2}{*}{$\begin{array}{l}\text { Relaxing monitoring } \\
\text { arrangements }\end{array}$} & $\begin{array}{l}\text { Quality assurance is } \\
\text { integrated into } \\
\text { commissioning } \\
\text { process }\end{array}$ \\
\hline & $\begin{array}{l}\text { Depends on } \\
\text { extensive data } \\
\text { collection }\end{array}$ & & $\begin{array}{l}\text { Prioritises feedback } \\
\text { from service users, } \\
\text { carers and provider } \\
\text { organisations, often } \\
\text { gathered in face to } \\
\text { face meetings }\end{array}$ \\
\hline
\end{tabular}

Commissioning relationships were beginning to change, evidenced by reciprocity, shared responsibility and trust, rather than a process of 'managing relationships' through formal meetings and forums. Trust, as a distinctive element of relational contracting, included components such as interdependency and the exercise of discretion in making decisions about care packages. Trust within a contractual relationship is fundamental to successful practice between commissioners and providers (Hudson 2004; Rubery, Grimshaw, Hebson, 2013; Högberg, Sköld and Tillmar, 2018). For instance, research from the Netherlands reported that most of their municipalities have adopted a relational contractual approach to social care rather than a competitive tendering model, which was cited as a source of conflict 
in the past (Uenk and Telgen, 2019). In the context of current commissioning arrangements in England, commissioners and providers may require a better understanding of the hallmarks of trust as they work together to provide home care services, answering questions such as, what are the indicators of being able to trust a provider or commissioner? What are the limits of trust? How can a providers' detailed knowledge of the relationship between 'inputs' with a service user and 'outcomes' be utilised by commissioners?

The relationship between the commissioner and the provider is poised in a delicate balance between vulnerability and power. In some instances, the provider has a privileged position, for example in their knowledge of the relationship between inputs and outputs, with commissioners relying on the provider for accurate information. In other cases, the commissioner is advantaged, using contracting frameworks to add or remove providers as necessary, remaining in control and potentially minimising local authority costs (in relation to the financial and administrative costs of monitoring and / or losing a provider). Such practices inevitably determined whether providers secured workflow and profit, thus transferring risk to the provider organisation (Rodrigues and Glendinning, 2015). Implications of managing the relationship on changes in the market cannot be easily predicted; troubling examples of providers losing interest in local authority contracts and opting out have been reported, with serious consequences for both service users and commissioners who hold the responsibility for ensuring the supply of providers (Hudson, 2015; Hudson, 2018).

The study had a number of strengths: the participants were deliberately identified from a broad range of contexts from a national survey, reflecting different approaches to commissioning. Employing semi-structured interviews enabled participants to talk openly and in-depth about the commissioning process. The main limitation of the study related to potential social desirability bias, with participants possibly expressing views that they considered are most acceptable and reflect well on their own activity. To reduce the influence of social desirability bias, the study used telephone interviews, introducing a distance between the interviewer and interviewee (Novick, 2008). Moreover, the topic guide comprised of questions probing broad 
topic areas that allowed a wide-ranging conversation and reflection, offering opportunities for follow up questions and probing. Furthermore, the interviewers were experienced in conducting research interviews and employed techniques such as pausing, prompting and clarifying to encourage more detailed responses.

\section{Conclusion}

Commissioning, as an approach to arranging social care adopted across many countries, is clearly an evolving process. In the English system, it has been changing in response to the complex context of the home care sector that depends on independent care providers to deliver services. Commissioners are adapting their approaches to reconcile the contradictory drivers of operating in a market model whilst achieving care that delivers personalised outcomes. Innovative developments and improvements depend on a collaboration with care providers and other stakeholders, rather than prescriptive contracts that cannot encompass the range of care that service users require. Working in partnership with providers is therefore a greater imperative than promoting competition. However, it is also seen as a 'tightrope' associated with risks of exploitation of commissioners and failure of services. Given that the relational approach is pivotal to encouraging effective provision of home care, a better understanding of the hallmarks of a trusting collaboration and the constraints of contracting will be essential for commissioners internationally, to influence the shift to responsive and flexible care and the elusive goal of value for money.

Statement of funding

This paper presents independent research funded by the National Institute for Health Research (NIHR), School for Social Care Research (SSCR). The views expressed in this article are those of the authors and not necessarily those of the NIHR SSCR or the Department of Health and Social Care, NIHR or NHS.

Author contributions: All the authors contributed to the design of the study, the collection and analysis of the data and reporting the findings. 
Conflict of interest. There are no conflicts of interest for the authors.

Ethical standards. The study employed standard ethical procedures to gain verbal consent from all participants.

Acknowledgements. The authors are grateful to all the commissioners who contributed so readily to this study.

\section{References}

Bamford, T (2013) Commissioning and purchasing. Routledge.

Bertelli A.M. and Smith C.R (2009) Relational contracting and network management. Journal of Public Administration Research and Theory, 20, 21-40.

Bottery S (2018). Home care in England: views from commissioners and providers. Kings Fund.

Bovaird, T (2006) Developing new forms of partnership with the 'market' in the procurement of public services. Public administration, 84, 81-102

Bovaird T (2016) The ins and outs of outsourcing and insourcing: what have we learnt from the past 30 years? Public Money \& Management, 36, 67-74.

Braun V. and Clarke V (2006) Using thematic analysis in psychology. Qualitative research in psychology, 3, 77-101.

Chester, H., Hughes, J. and Challis, D (2010) Patterns of commissioning, contracting and care management in social care services for older people in England. British Journal of Social Work, 40, 2523-2537.

Coleman A. Checkland K. and Harrison S (2009) Still puzzling: patient and public involvement in commissioning. Journal of Integrated Care, 17, 23-30.

Crosby B.C, 't Hart P and Torfing J (2017) Public value creation through collaborative innovation, Public Management Review, 19, 655-69

Care Quality Commission (2017) The state of health care and adult social care in England 2016/17, Care Quality Commission (October 2017). Retrieved from: https://www.cqc.org.uk/sites/default/files/20171123 stateofcare1617 report.pdf

Cm 8378 (2012) Caring for Our Future: Reforming Care and Support, Department of Health and Social Care, London

Davies, H., Nutley, S. and Smith, P (2000) Introducing evidence-based policy and practice in public services. What works,1-12.

Davies K. and Davies P (2012) Tensions in commissioning: services for children's speech, language and communication needs in one English region. Journal of health services research \& policy, 17, 37-44

Davies, S. Hughes, J., Chester, H, Davies, K., Jasper, R., Roberts, A. Challis, D (2019) Changes in commissioning home care: an English survey. Quality in Ageing and Older Adults, 176-193 
Department of Health and Social Care (2014) Adult Social Care Outcomes Framework. London.

Department of Health and Social Care (2018) Care and support statutory guidance.

Available at: https://www.gov.uk/government/publications/care-act-statutoryguidance/care-and-support-statutory-guidance\#chapter-4 (Accessed April 2019).

Glendinning C. Clarke S. Hare P. Kotchetkova I. Maddison J. and Newbronner L (2006) Outcomes-focused services for older people -progress and possibilities. SPRU: York.

Glendinning C. Clarke S. Harre P. and Maddison J (2008) Progress and problems in developing outcome-focused social care services for older people in England. Health \& Social Care in the Community, 16, 54-63.

Henwood M (2019) Self-funders and Social Care: from bystanders to core participants? Available at: https://www.birmingham.ac.uk/schools/social-policy/departments/healthservices-management-centre/news/viewpoint/2019/01/self-funders-and-social-care.aspx (Accessed April 2019).

Högberg L. Sköld B. and Tillmar M (2018) Contextualising the coevolution of (dis)trust and control - a longitudinal case study of a public market, Journal of Trust Research, 8 , $192-219$

Holmes J (2016) An overview of Domiciliary Care Market in UK. UKHCA. Wallington Hudson B (2004) Trust: Towards conceptual clarification. Australian Journal of Political Science, 39,75-87.

Hudson B (2013) Competition and Collaboration in the New NHS. Centre for Health and the Public Interest.

Hudson B (2015) Dealing with market failure: A new dilemma in UK health and social care policy? Critical Social Policy, 35, 281-92.

Hudson B (2018) Adult social care: is privatisation irreversible? London School of Economics. https://blogs.Ise.ac.uk/politicsandpolicy/adult-social-care-is-privatisationirreversible/ Accessed in March 2019.

Knapp M. Hardy B. and Forder J (2001) Commissioning for quality: ten years of social care markets in England. Journal of social policy, 30, 283-306.

Kings Fund (2017) What is commissioning and how is it changing.

https://www.kingsfund.org.uk/publications/what-commissioning-and-how-it-changing

Accessed $1^{\text {st }}$ May 2019

lacobucci G (2019) NHS England sets out plan to revoke Lansley's competition rules. BMJ 364,1990

Isaksson D. Blomqvist P. and Winblad U (2018) Privatization of social care delivery-how can contracts be specified? Public Management Review, 20,1643-62.

Jasper, R., Hughes, J., Roberts, A., Chester, H., Davies, S., Challis, D (2019) Commissioning home care for older people: scoping the evidence. Journal of Long Term Care

Local Government Association (2018) National procurement strategy.

https://www.local.gov.uk/sites/default/files/documents/national-social-care-cate-468.pdf. Accessed $1^{\text {st }}$ May 2019 
Mackintosh M (2000) Flexible contracting? Economic cultures and implicit contracts in social care. Journal of Social Policy, 29,1-19.

Moran, N., Glendinning, C., Wilberforce, M., Stevens, M., Netten, A., Jones, K., Manthorpe, J., Knapp, M., Fernández, J.L., Challis, D. and Jacobs, S (2013) Older people's experiences of cash-for-care schemes: evidence from the English Individual Budget pilot projects. Ageing \& Society, 33, 826-851.

Newman M. Bangpan M. Kalra N. Mays N. Kwan I. and Roberts T (2012) Commissioning in health, education and social care: models, research bibliography and in-depth review of joint commissioning between health and social care agencies. Technical Report. EPPI-Centre, Social Science Research Unit, Institute of Education, University of London, London

Novick G (2008) Is there a bias against telephone interviews in qualitative research? Research in nursing \& health, 31, 391-98.

Porter A. Mays N. Shaw S.E. Rosen R. and Smith J (2013) Commissioning healthcare for people with long term conditions: the persistence of relational contracting in England's NHS quasi-market. BMC Health Services Research, 13, S2.

Raynes N. Temple B. Glenister C. and Coulthard L (2001) Quality at Home for Older people: Involving service users in designing home care specifications, Bristol: Policy Press.

Robinson S. Dickinson H. Durrington L (2016) Something old, something new, something borrowed, something blue? Reviewing the evidence on commissioning and health services. Australian Journal of Primary Health 22, 9-14.

Rodrigues R. and Glendinning C (2015) Choice, competition and care-developments in English social care and the impacts on providers and older users of home care services. Social Policy \& Administration, 49, 649-664.

Rubery J.Grimshaw D. and Hebson G (2013) Exploring the limits to local authority social care commissioning: competing pressures, variable practices, and unresponsive providers. Public Administration, 91, 419-437.

Smith R. Darton R. Cameron A. Johnson E.K. Lloyd L. Evans S. and Porteus J (2017) Outcomes-based commissioning for social care in extra care housing: is there a future? Housing, Care and Support, 20, 60-70.

Uenk N. and Telgen J (2019) Managing challenges in social care service triadsExploring public procurement practices of Dutch municipalities. Journal of Purchasing and Supply Management, 25, 5-17.

Van Slyke D.M (2006) Agents or stewards: Using theory to understand the governmentnonprofit social service contracting relationship. Journal of public administration research and theory, 17, 157-187.

Ware T. Matosevic T. Hardy B. Knapp M. Kendall J. and Forder J (2003) Commissioning care services for older people in England: the view from care managers, users and carers. Ageing \& Society, 23, 411-28.

Wilberforce M. Baxter K. and Glendinning C (2012) Efficiency, choice and control in social care commissioning. Public Money \& Management, 32, 249-256. 